\title{
SELECTION OF WORM GEARING OPTIMAL STRUCTURE FOR MACHINE ROTARY TABLE
}

\author{
Oleg KROL, Volodymyr SOKOLOV \\ Volodymyr Dahl East Ukrainian National University, Department of Machinery Engineering \\ and Applied Mechanics, 59-a Central pr., Severodonetsk, 93400, Ukraine \\ e-mail: krolos.snu.edu@gmail.com
}

\begin{abstract}
In this paper, the design of the machine rotary table with a kinematic worm gearing is research. A threedimensional model of the rotary table assembly structure and the stress-strain state of the worm by the finite element method are researched. Optimization of the worm gearing design with a helicoidally worm as a multivariate problem of optimizing the total minimum length of contact lines in a worm engagement is presented. A feature of this article is the search for such a combination of worm gear input parameters that optimize the characteristics of contact lines by the criterion of minimum contact stresses. As a limiting factor for the criterion of contact length, the coefficient of oscillation within a certain average value obtained experimentally is taken. The nature of the extremal function of the contact length depending on the values of the variable's derivative reflecting the influence of the number of worm threads and gear ratio is investigated. The effect of the shifting coefficient with the optimal search for the maximum contact length within the standard values of the worm diameter coefficient is shown. An algorithm and an analytical form for the development of a more advanced worm gearing with increased efficiency are proposed.
\end{abstract}

Keywords: worm engagement, workpiece-turning mechanism, 3D model, contact line, contact stress

\section{INTRODUCTION}

In the modern machine-tool industry, the proportion of multifunctional metal-cutting machine tool complexes realizing the production of various designs with complex form-forming movements is increasing. Increasingly, additional modular equipment expanding technological capabilities is being used - various types of tool storages, overhead rotary tables, and spindle heads with integrated precise positioning units. A variety of periodic rotation devices with subsequent fixation of the location of the forming units are widely used in modern $\mathrm{CNC}$ machines and machine complexes [1,2].

The quality of products depends on the accuracy of the main forming movements [3]. In a wide range of drilling, milling and boring machines, fairly standardized designs of rotary tables are used. The efficiency of their use is limited by the magnitude and direction of the applied load in the cutting zone, as well as the layout in the kinematic structure of the machine, including the direction of the rotation axis and location relative to the main drive and spindle heads of the milling machine. In turn, the quality of manufactured parts processing depends on the rotation speed of the table and the accuracy of fixation in the working position.

The magnitude and direction of the force determine the rigidity of the rotary table structural elements that perceive them. The layout of the table as part of the equipment, as well as the necessary speed of its rotation and fixation, significantly the type of drive is determined. The accuracy of the table fixed position determines, first, the design of the locking mechanism. Rotary tables can have the following types of drive: mechanical (electromechanical), hydraulic and combined. In machine tools, the most common is an electromechanical worm gear drive.

Used machine dividing worm gears of 6-7 degrees of accuracy can be performed with both adjustable and unregulated center distance. Moreover, in both cases, the most objective indicator of the quality in the transmission is the total tooth bearing with normalization along with the height and length of the teeth. Moreover, an increase in the size of the tooth bearing leads to an increase in the load capacity and operating life of the transmission. In turn, the tooth bearing is associated with the parameter of the contact lines length in the worm engagement.

Design and modernization of the structure of the rotary tables with drive worm gears in various computer-aided design systems are carried out [4]. Given the specifics of the products under consideration, the availability of regulatory design documentation is promising the use of CAD/CAM/CAE KOMPAS-3D [5-7]. 


\section{LITERATURE REVIEW}

Various designs of rotary tables are considered in [8-11]. In [8] an analysis of many design options for the implementation of five-axis rotary tables with dimensions not exceeding $100 \mathrm{~mm}$ was made. It is noted that the construction in which the clearance in the worm gear is compensated ("AntiBacklash Gears" [9]) is promising. Adjusting screws as a pre-adjustment mechanism to compensate for the lateral clearance between the worm and the worm wheel are used. Another interesting option is to use a spring-loaded worm gear ("Spring Loaded Gear Mesh") [10]. This version with a pre-loaded spring is introduced in the pilot design of a 5-coordinate small-sized rotary table for the Haas vertical machining center of the OM-2 model.

In [11], a new drive in the structure of a rotary table is proposed. An unconventional transmission based on a roller-cam mechanism including a globoid cam with a unique profile and a special roller mechanism is proposed. Moreover, the creation of backlashless engagement with preload at the assembly level of the structure under consideration is carried out. In contrast to the design discussed above [8], such roller-cam mechanisms can serve as a drive device in rotary tables of various dimensions from 100 to $1500 \mathrm{~mm}$. However, under heavy loads during wear of the rotary mechanism elements, compensation of lateral gaps in the engagement zone is necessary.

In $[12,13]$, an analytical approach for static and dynamic analysis of a rotary system, as well as for ensuring its vibration reliability were proposed. Additionally, in [14], an analysis of the gear tooth gearing by the specific module for equipment was presented. Moreover, in [15], the implementation of artificially intelligent systems for the fault diagnostics of technical systems was realized.

In the reversing mechanisms of machine tools and machine tool complexes, the use of classical mechanical transmissions, such as a worm transmission, is difficult due to the problem of strict synchronization of rotations of the driving and driven shafts $[16,17]$. This situation occurs during the reverse movement of the worm when the driven worm wheel is stationary for a certain period. Inconsistency of the worm wheel movement is associated with the presence of gaps in the engagement. The mismatch of the worm transmission elements rotations causes inaccuracy in the positioning of the machine rotary table. Analyzing the methods of clearance-free gearing implementation, two approaches can be distinguished: the first with the search for a new technology for the production of worm gear elements is connected; the second involves the use of special devices to compensate for gaps in worm engagement. The problems present in these two approaches to the complication of both the production process and the design of gapless worm engagement are related.

There are several problems associated with the analysis of the engagement zone [18, 19, 20], which are characteristic of various types of mechanical gears (spur, helical, bevel, worm, etc.). Large-scale researches of the various types of mechanical gears designs in developed computer-aided design systems and authoring specialized software are carried out. So, in the ABAQUS program environment, dual-part gearing research was conducted, aimed at modelling and determination of contact stresses on the lateral surfaces of teeth (tooth flank) and bending stresses at the tooth root [21]. The author emphasizes that the level of bending stresses in the tooth root on the side opposite to the applied load is two times lower than in the case of contact stresses on the flanks of the mating teeth, which corresponds to the gearing theory. Of interest are also the author's two specialized subprograms [22] as part of the ABAQUS program. The latter allows importing a $3 \mathrm{D}$ model from other CAD systems (in this case, from CATIA software). The proposed routines make it possible to evaluate the level of contact stresses, the pressure on the lateral surfaces of the tooth and the size of the tooth bearing, and therefore the length of the contact lines.

The paper [23] is devoted to the creation of solid models of bevel drive gearwheels in an Autodesk Inventor environment and the modelling of the main engagement parameters. The authors developed a new method for determining the contact line and the line of bevel gears engagement. To this purpose, the design of the gearbox by adding element in the form of a sphere with a small radius relative to the pinion was modified. During the research, a procedure was proposed for generating the contact path and the line of engagement with preliminary determination (on the complex shape of the contact surfaces) of the central point's geometric parameters of the tooth bearing.

As [24] rightly claims, one of the research main goals of mechanical transmissions is to create a working 3D model for analyzing contact geometry, visual identification, and evaluating the ratios of many tooth geometric parameters. The composition of the designer's toolkit should include a method for creating a gearwheel three-dimensional model in the corresponding integrated CAD systems $[4,6$, 7].

An analysis of the above works showed that research directions to improve the performance criteria of the drive mechanisms for the rotary tables of metal cutting machines are associated with the creation of gapless worm transmissions and the improvement of their designs. A large reserve in improvement by searching for the optimal ratio of transmission parameters to maximize the effective operation of machine tools equipment can be achieved. 
Based on the analysis of the problem under consideration to achieve a more efficient functioning of machine tool machines with rotary tables, we will make the following statement of the problem:

To develop a search procedure for the optimal design of the worm transmission for the machine rotary table by determining the optimal ratio of the main gearing engagement parameters.

To achieve this goal, the following tasks are proposed:

1. To develop 3D models of the machine tool's rotary table using CAD KOMPAS-3D with the built-in application "Shafts and mechanical transmissions-3D".

2. To research the effects of the worm transmission's input parameters and determine their optimal ratio from the standpoint of the performance criterion.

\section{CREATION OF THE 3D MODELS FOR DRILLING-MILLING-BORING MACHINE ROTARY TABLE}

As a design object, we consider a specialized multi-operational machine with $\mathrm{CNC}$ of the milling-drilling-boring type second standard size based on the model SVM1F4. The machine can process vertical, horizontal, and inclined planes, shaped surfaces, holes, grooves by various technological methods: milling, drilling, countersinking, and reaming.

a)

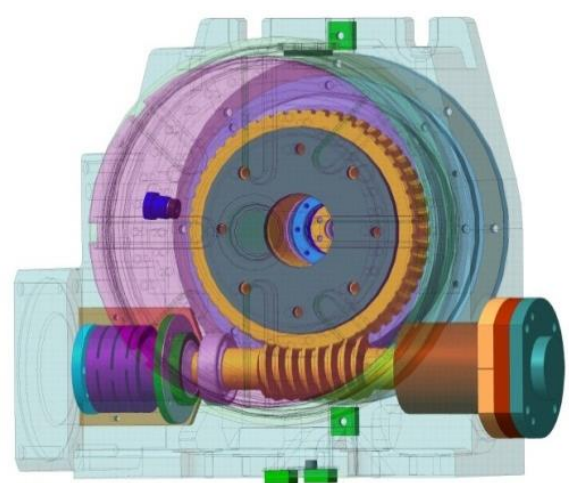

c)

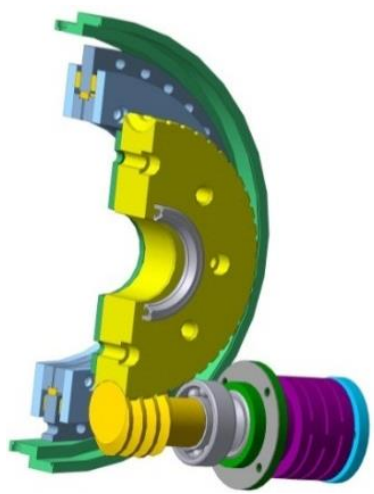

For the automated manipulation of workpieces and cutting tools of various sizes and shapes in this machine, additional modular tooling as part of the feed drive, which allows implementing a large number of different technological operations without remounting the machined parts is used. In the context of the production of an increasing number of machine tool sizes and constant changes in the configuration of workpieces, the design and manufacture of a rotary tables line equipped with hydromechanical drives are promising $[25,26]$.

To analyze the design operability and select the optimal design $[27,28]$ for the rotary table of the CNC machine tool model SVM1F4.

Requirements for rotary tables:

- high (up to $2 \mu \mathrm{m}$ ) accuracy of positioning of a rotary table when using correction systems;

- accuracy of reversal, for providing dynamic compensation of errors;

- implementation of the minimum (up to $5 \mu \mathrm{m}$ ) pulse displacement.

To solve the problems of modelling modified machine tool structures, it is effective to use the integrated CAD KOMPAS-3D using the specialized application "Shafts and mechanical transmissions-3D". This system can serve as a platform for creating a specialized application for the design of workpiece turning mechanisms on metal cutting machines. A 3D model was created in KOMPAS-3D CAD system, consisting of more than 300 parts (Fig. 1).

b)

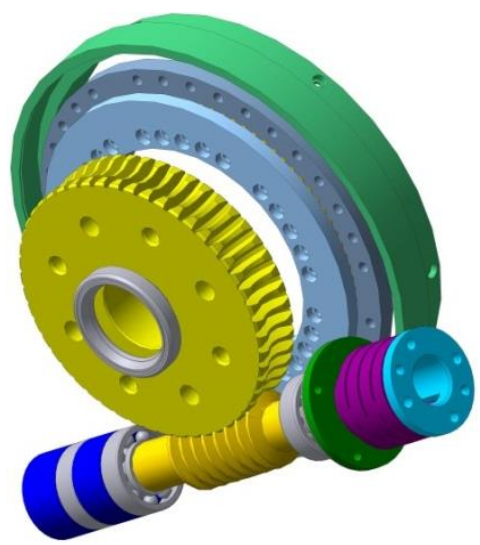

d)

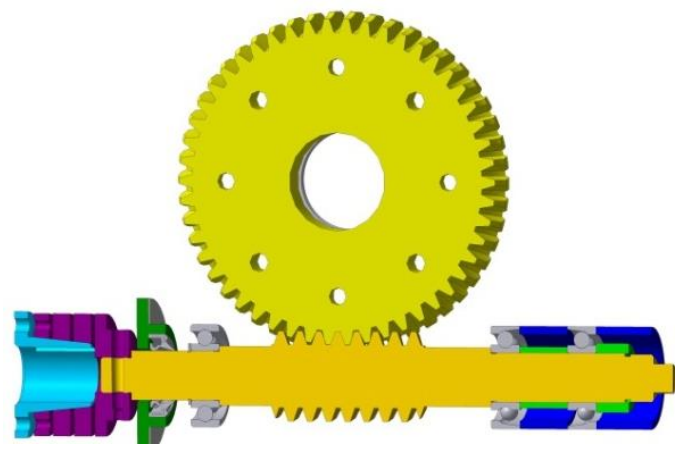

Fig. 1. A three-dimensional model of a rotary table with a faceplate: a - general view with the option of transparency; $\mathrm{b}$ - worm transmission; $\mathrm{c}, \mathrm{d}$ - sections of the worm gear with a special bearing 
The rotary controlled table (Fig. 1) is made in the form of an independent unit mounted on the machine corner table in two positions with a vertical and horizontal axis, depending on the location of the surface being machined.

The table consists of a housing in which a worm pair is located, transmitting movement from a hightorque engine to an actuating element - a faceplate (Fig. 1, a). The rotary table is controlled using a CNC through a circular inductosin PUI-18A. The rotation of the faceplate at a given angle is controlled by an optical sensor mounted on the vertical axis of the rotary table. The fastening of parts to the rotary table by T-grooves located on the faceplate is made. Changing the working speed of the rotary table faceplate is smoothly in the range from 0.1 to $3.5 \mathrm{~min}^{-1}$, accelerated movement is 6.5 $\mathrm{min}^{-1}$. In the case of a rotary table with a horizontal axis, a tailstock is used to maintain the cantileverlocated part.

The main mechanical transmission that determines the reliability of the feed drive is a worm transmission. In the environment of KOMPAS-3D, the design was carried out and a three-dimensional model of worm gear elements was created (Fig. 1). For this, the special application "Shafts and mechanical transmissions-3D" [29, 30] was used. To increase the accuracy of the worm wheelbase in the rotary table drive, it is not enough to use only one conical seating surface (Fig. 1, d). It is also necessary to provide for based on the end surface. To ensure the synchronization of the worm and the wheel, the design of the gapless worm gear is used.

For a more complete description of the stressstrain state of the designed worm transmission, the finite element method in the APM FEM module was used [31, 32, 33]. Using this module, the stressstrain state of arbitrary geometric shape objects under arbitrary loading and fastening is calculated (Fig. 2).

When simulating the parameters of contact interaction in the APM FEM module, an uneven distributed load in the worm-worm wheel contact zone. In this case, the distribution law is used with the maximum loading values at the root of the worm thread is specified.

In the process of researching the worm gear in the APM FEM module, equipped with a finite element mesh generator, included in the CAE library [31], a finite element mesh was constructed (Fig. $2 a)$, with the number of finite elements 11515 , and the number of nodes for rod elements more than 3000. When choosing the partition characteristics of various worm sections (flat finite elements of arbitrary shape "fit" into these sections), an adaptive partition in the form of an uneven grid was used. This allows for a more accurate fit of finite elements into complex cross-sections. First, this refers to the engagement zones on the flanks of the worm tooth and the tooth root.

In the APM FEM system, each finite rod element includes two nodes that have 6 degrees of freedom. The interaction of finite elements with each other is realized through their nodes, taking into account that a stiffness matrix is formed, the solution of which reduces to solving a system of algebraic equations. A joint solution to the system of equations is the magnitude of the stresses (Fig. 1, b) and the magnitude of the displacements (Fig. 1, c). The calculation of the rod elements taking into account all stress concentrators is carried out. This allows to more accurately determine the magnitude of the current stress.

During the design process, matching faces are determined (for FE analysis of the assembly); FE mesh generation by the MT Frontal method (using processor multicore); calculation and viewing of results in the form of stress and displacement maps is performed. Within the framework of the APM FEM module, all of the above actions were carried out and received:

- Mises equivalent stress fields (fourth strength theory), presented in Fig. 2b;

- fields of displacements (Fig. 2, c) on the set of sections of the worm.

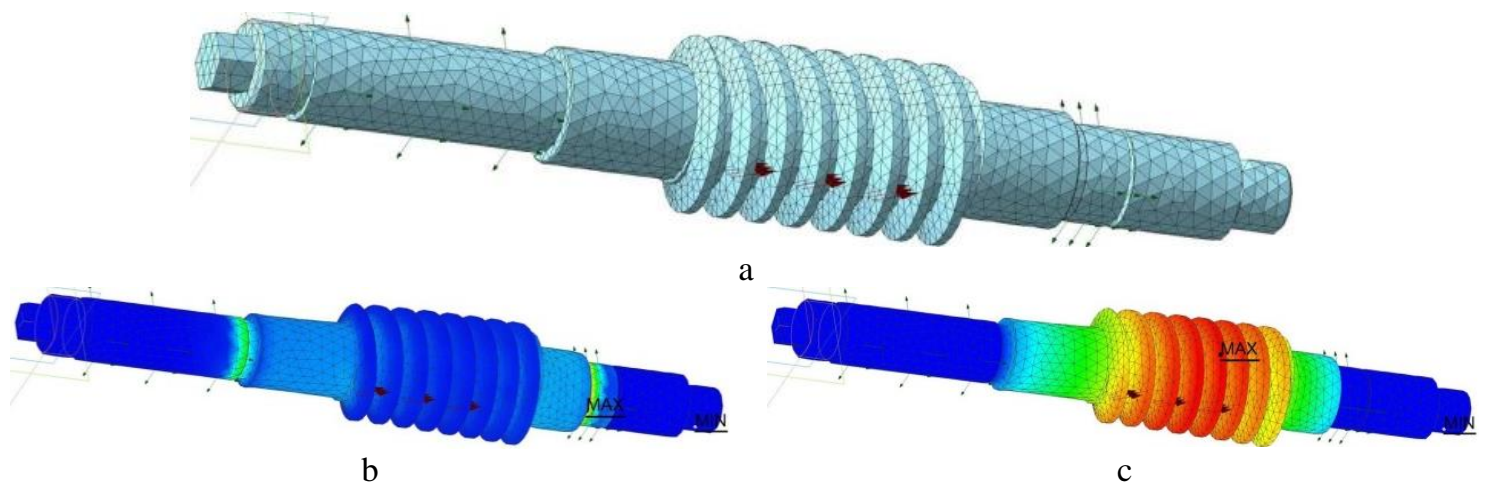

Fig. 2. Finite-element analysis of the worm: a - finite-element mesh, supports, and loading; $\mathrm{b}$ - stress fields; $\mathrm{c}-$ displacement fields 


\section{RESULTS AND DISCUSSION}

The optimization of the worm gear design with a helicoidally worm $[29,34,35]$ is a multivariate task, the solutions of which in its various statements are given in $[16,17]$. Combinations of numerical values of the engagement parameters: the number of worm threads $z_{1}$, the number of worm wheel teeth $z_{2}$ and the worm diameter factor $q$ (the quotient of reference diameter to the axial module) which depend not only on the gear ratio $u$ but also on what performance criterion is set as the main one. The shape and length of the contact lines of the worm gear significantly affect the reliability of its operation, including indicators such as contact endurance and wear resistance of the wheel teeth working surfaces. In addition, since contact stresses $\sigma_{H}$ are interconnected with the indicated criteria, its values are largely determined by the total length of the contact lines in engagement $L_{\Sigma}$. Moreover, as is known from the contact problem of G. Hertz, the value $\sigma_{H}$ is inversely proportional $\sqrt{L_{\Sigma}}$, which in the process of worm gearing varies from $L_{\Sigma \min }$ to a certain maximum value $L_{\Sigma \max }$. The calculation $\sigma_{H}$ is based on the total minimum length $L_{\Sigma}=L_{\Sigma \text { min }}$, since in this phase of engagement $\sigma_{H}=\sigma_{H \max }$. Therefore, minimization $\sigma_{H}$ is associated with the possibility of obtaining the maximum possible value $L_{\Sigma \text { min }}$ for the given transmission parameters.

If the shape of the contact lines mainly depends on the type of worm (these are standard ZA, ZJ, ZN, $\mathrm{ZT}$, as well as worms with new original profile), then the length of the contact lines for the same type the worm varies depending on a combination of numerical values of transmission parameters such as $z_{1}, z_{2}, q$.

The article presents the research results of the influence of parameters $z_{1}, z_{2}, q$ on the total minimum length of contact lines $L_{\Sigma \min }$ in the field of engagement of the worm gear with the standard original contour of the worm.

The initial dependence for $L_{\Sigma \min }$ :

$$
L_{\Sigma \min }=\pi \cdot d_{1} \cdot \frac{2 \gamma}{360} \cdot \frac{\xi^{\prime} \cdot \varepsilon_{S}}{\cos \gamma}
$$

where $d_{1}=m \cdot q$ - reference diameter of the worm;

$\gamma=\arcsin \left(\frac{b_{2}}{d_{a 1}-0.5 \cdot m}\right)-$ the conditional angle of contact;

$b_{2} \leq 0.75 \cdot d_{a 1}-\xi^{\prime}=L_{\Sigma \min } / L_{a v g} \approx 0.75$ - the worm wheel face width;
$\xi^{\prime}=L_{\Sigma \min } / L_{a v g} \approx 0.75-$ coefficient taking into account the fluctuation $L_{\Sigma}$ from $L_{\Sigma \min }$ to a certain average value $L_{\text {avg }}$;

$\varepsilon_{S}=\frac{\sqrt{r_{a 2}^{2}-r_{2}^{2} \cdot \cos ^{2} \alpha}-r_{2} \cdot \sin \alpha+m \cdot(1-x) / \sin \alpha}{\pi \cdot m \cdot \cos \alpha}-$ the overlapping coefficient in the mean end plane of the worm wheel, [6]; (here it is accepted $\alpha=20^{\circ}-$ the angle of the threads on the diameter $d_{1}$ ).

After substituting the parameters, included inequality (1), the calculated dependence for takes the form:

$$
L_{\Sigma \min }=L_{\Sigma \text { min }}(m, q) \approx 4 \cdot m \cdot \sqrt{q+1-2.8 \cdot x},
$$

here $m=2 \cdot a_{W} /\left(z_{2}+q\right)$ - gearing module; $x-$ worm-shifting coefficient.

We introduce a new variable $s=q / z_{1}$ and substitute it into equation (2). As a result, the twoparameter function $L_{\Sigma \min }=L_{\Sigma \text { min }}(m, q)$ is replaced by the equivalent one-parameter function $L_{\Sigma \text { min }}=L_{\Sigma \min }(s)$ :

$$
L_{\Sigma \min }=L_{\Sigma \min }(s)=\frac{8 \cdot a_{W}}{z_{1}} \cdot \frac{\sqrt{s \cdot z_{1}+1-2.8 \cdot x}}{u+s},
$$

where $u=z_{2} / z_{1}$ - gear ratio.

We search for optimal values $\left[z_{1}, z_{2}, q\right]$ corresponding to the value $L_{\Sigma \text { min }}(s)=\max$ using a variable $s=q / z_{1}$, for which we examine the function (3) for extremum:

$$
\frac{d L_{\Sigma \min }(s)}{d s}=\left(\frac{8 \cdot a_{W}}{z_{1}} \cdot \frac{\sqrt{s \cdot z_{1}+1-2.8 \cdot x}}{u+s}\right)_{S}^{\prime}=0 .
$$

The result of solving equation (4) is the dependence:

$$
s=s\left(z_{1}, u\right)=\frac{z_{1} \cdot u+5.6 \cdot x-2}{z_{1}},
$$

which gives the values of the variable $s$ at which the total minimum length of the contact lines (lines of action) of the worm gear will be maximum, i.e. $L_{\Sigma \min }(s)=\max$.

The plots $L_{\Sigma \min }=L_{\Sigma \min }(s)$ for $z_{1}=1,2,4$ are presented in Fig. 3. It can be seen from them that function (3) has extremum that corresponds to values $L_{\Sigma \min }(s)=\max$ for various $s$.

However, extreme values $s$ at which $L_{\Sigma \min }(s)=\max$, are not acceptable for worm gears with standard values $q=6.3 \ldots 24$ [34]. So, for curve $1\left(z_{1}=1\right)$, the point of the function $L_{\Sigma \min }(s)=\max$ falls on $s=q / z_{1}=50$. It follows that: 


$$
q=s \cdot z_{1}=50 \cdot 1=50
$$

which is more than two times the maximum $q=24$, stipulated by the standard [34].

The same picture takes place on curve 2, constructed for $z_{1}=2$ and curve 3 - for $z_{1}=4$, Fig. 3 . Optimum values: $s=s_{\text {opt }}$ and for $q=q_{\text {opt }}=s_{\text {opt }} \cdot z_{1}$, which the theoretical length of the contact lines are given in the table:

Table 1

\begin{tabular}{|r|r|r|r|}
\hline$z_{\text {opt }}$ & 1 & 2 & 4 \\
\hline$q_{\text {opt }}$ & 50 & 25 & 12.5 \\
\hline & 50 & 50 & 50 \\
\hline
\end{tabular}

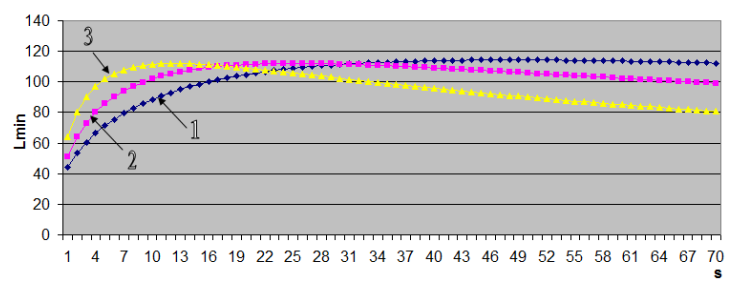

Fig. 3. Dependency $L_{\Sigma \min }$ on variable $s=q / z_{1}$ : Curve 1: $\left\{\begin{array}{l}z_{1}=1 ; \\ u=50 .\end{array}\right.$ Curve 2:

$$
\left\{\begin{array} { l } 
{ z _ { 1 } = 2 ; } \\
{ u = 2 5 }
\end{array} \text { Curve 3: } \left\{\begin{array}{l}
z_{1}=4 ; \\
u=13
\end{array}\right.\right.
$$

The shifting coefficient $x$, which has a noticeable effect on the length of the contact lines $L_{\Sigma \min }$, does not significantly change the $s$ value, at which $L_{\Sigma \min }(s)=\max$, Fig. 4 .

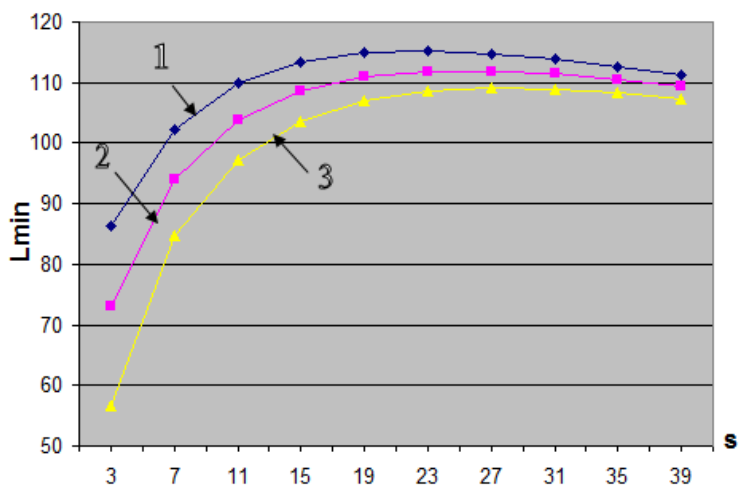

Fig. 4. The effect of the shifting coefficient $x$ on the value $L_{\Sigma \min }$ : curve $1(x=-1)$; curve 2 $(x=0)$; curve $3(x=+1)$

The function graphs $L_{\Sigma \text { min }}=L_{\Sigma \text { min }}(s)$ for dual lead worms $\left(z_{1}=2\right)$ at various shifting coefficients $x$ are plotted. The graphs show that for $s \approx 23 \ldots 27$, those in the area $s_{\text {opt }}=25$, the change $L_{\Sigma \text { min }}$ for each of the values of $x=[-1 ; 0 ;+1]$ is very small (less than 1\%). On the other hand, as $x$ increases from -1 to +1 , the total minimum length of the contact lines $L_{\Sigma \min }$ decreases markedly. So, for $z_{1}=2$ and $s=9$ (this corresponds to $q=s \cdot z_{1}=9 \cdot 2=18$, that within the standard $\left.q\right)$, when passing from curve $1(x=-1)$ to curve 3 ( $x=+1)$, Fig. 4 , the value $L_{\Sigma \text { min }}$ decreases by almost $30 \%$. Thus, negative $x$ values from $L_{\Sigma \min }(s)=\max$ an achievement point of view are preferred.

\section{CONCLUSION}

The design of the rotary table of drilling, milling and boring machine tools with a modified worm transmission has been developed. The complex of 3D models of the rotary table, including more than 300 parts, is built in the environment of the integrated CAD KOMPAS-3D using the specialized application "Shafts and mechanical transmissions3D". The use of geometrically complex graphic primitive's characteristic of worm gearing allows increasing the productivity of the designer by $1.3 \ldots$ 1.5 times. The research of the stress-strain characteristics for the worm in the APM FEM module with an adaptive finite element mesh generator on the flank surfaces of the tooth and its root is realized. Fields of stresses and displacements were constructed to visualize the distribution of deformations in the contact zone of the worm and the worm wheel under conditions of unevenly distributed load, with an increase in the worm's thread in the root zone. The results of the study for the parameters $z_{1}, z_{2}, q$ influence the total minimum length of contact lines $L_{\Sigma \text { min }}$ in the field of the worm gear engagement with the worm standard initial contour are presented. A mathematical model for the dependence of the minimum length $L_{\Sigma \min }$ on the engagement parameters is constructed. A new variable $s=q / z_{1}$ is introduced, and the optimal values $\left\{z_{10}, z_{20}, q_{0}\right\}$, that return the optimum $L_{\Sigma \text { min }}$ are found. It is shown that to obtain standard (permissible) values $q \leq 24$, of the worm diameter factor, it is necessary to change the shifting coefficient $x$ in the range from -1 to +1 and negative values are preferable from the standpoint of maximization $L_{\Sigma \min }$. As a result, the contact stresses $\sigma_{H}$ in the engagement and the wear rate of the worm gearing working surfaces decrease. The dependency graphs $L_{\Sigma \min }=f(s)$ are constructed and it is proved that for a dual lead worm when passing from $x=+1$ to $x=-1$, the value $L_{\Sigma \min }$ increases by almost $30 \%$.

\section{REFERENCES}

1. Pronikov AS, Borisov EI, Bushuev VV et al. Design of metal-cutting machines and machine-tool systems: 
Handbook-textbook. In 3 volumes. Vol. 2. Part 1. Calculation and design of units and elements of machine tools. Moscow: Mashynostroenye, 1995. Russian.

2. Avramova TM, Bushuev VV, Gilova LYa. Handbook on metal-cutting machine tools. Moscow: Mashynostroenye, 2012. Russian.

3. Kotliar A, Basova Y, Ivanova M, Gasanov M, Sazhniev I. Technological assurance of machining accuracy of crankshaft. In: Diering M., Wieczorowski M., Brown C. eds. Advances in Manufacturing II. Manufacturing 2019. Lecture Notes in Mechanical Engineering. Springer, Cham; 2019. https://doi.org/10.1007/978-3-030-18682-1 4

4. Dobrotvorskiy S, Basova Y, Dobrovolska L, Sokol Y, Kazantsev N. Big challenges of small manufacturing enterprises in industry 4.0. In: Ivanov V, Trojanowska J, Pavlenko I, Zajac J, Peraković D. (eds) Advances in Design, Simulation and Manufacturing III. DSMIE 2020. Lecture Notes in Mechanical Engineering. Springer, Cham 2020; 118-127.

https://doi.org/10.1007/978-3-030-50794-7_12

5. Ganin N. Three dimensional modelling in KOMPAS3D. Moscow: DMK Publishing house, 2012. Russian.

6. Krol O, Sokolov V. Parametric Modeling of Gear Cutting Tools. In: Gapiński B, Szostak M, Ivanov V. (eds) Advances in Manufacturing II. Manufacturing 2019. Lecture Notes in Mechanical Engineering. Springer, Cham 2019; 4: 3-11. https://doi.org/10.1007/978-3-030-16943-5_1

7. Krol O, Sokolov V. Parametric modeling of transverse layout for machine tool gearboxes. In: Gapiński B, Szostak M. Ivanov V. (eds) Advances in Manufacturing II. MANUFACTURING 2019. Lecture Notes in Mechanical Engineering. Springer, Cham 2019; 4: 122-130. https://doi.org/10.1007/978-3-03016943-5_11.

8. Bass D, Riedl R, Slagle N. 4th and 5th Axis Rotary Table. Mechanical Engineering Department. California Polytechnic State University, San Luis Obispo; 2016.

9. Mauro G. Anti-Backlach Mechanism for a Rotary Stage. US Patent 6,016,716A, 18 Jun 1996.

10. Jozwik J, Czwarnowski M. Angular positioning accuracy of rotary table and repeatability of five-axis machining centre DMU 65 monoblock. Advance in Science and Technology Research Journal 2015; 9(28): 89-95.

https://doi.org/10.12913/22998624/60792

11. Dassanayake M, Tsutsumi M. High performance rotary table for machine tool applications. International Journal of Automation Technology 2009; 1: 343-347. https://www.researchgate.net/publication/304183144

12. Pavlenko I. Static and dynamic analysis of the closing rotor balancing device of the multistage centrifugal pump. Applied Mechanics and Materials 2014; 630: 248-254.

https://doi.org/10.4028/www.scientific.net/amm.630.248

13. Pavlenko I, Trojanowska J, Gusak O, Ivanov V, Pitel $\mathrm{J}$, Pavlenko V. Estimation of the reliability of automatic axial-balancing devices for multistage centrifugal pumps. Periodica Polytechnica Mechanical
Engineering 2019;63(1):52-56.

https://doi.org/10.3311/PPme.12801

14. Krivosheya AV, Voznyy VV, Melnyk VE. Analysis of the gear tooth gearing by the module $\mathrm{m}=2.625 \mathrm{~mm}$ of hydraulic pumps. Journal of Engineering Sciences 2017; 4(1): A11-A15.

https://doi.org/10.21272/jes.2017.4(1).a2

15. Altaf S, Mehmood MS, Imran M. Implementation of efficient artificial neural network data fusion classification technique for induction motor fault detection. Journal of Engineering Sciences 2018; 5(2): E16-E21. https://doi.org/10.21272/jes.2018.5(2).e4

16. Bernatsky IP, Vyushkin NI, Gerasimov VK, Komkov VN. The rational choice of the gearing parameters for worm gears. Gear and worm gears. 1974; 193-210. Russian.

17. Levitan YuV, Obmornov VP, Vasiliev VI. Worm reducers: Handbook. Leningrad: Mashynostroenye, 1985. Russian.

18. Litvin FL. The theory of gearing. Moscow: Nauka, 1968. Russian.

19. Litvin FL, Qi Fan, Fuentes A. Computerized Design, Generation, Simulation of Meshing and Con.tact of Face-Milled Formate Cut Spiral Bevel Gears", NASA/CR-2001

20. Permyakov A, Dobrotvorskiy S, Dobrovolska L, Basova Y, Ivanova M. Computer modeling application for predicting of the passing of the high-speed milling machining hardened steel. In: Ivanov V. et al. (eds) Advances in Design, Simulation and Manufacturing. DSMIE 2018. Lecture Notes in Mechanical Engineering. Springer, Cham. 2018. https://doi.org/10.1007/978-3-319-93587-4_15

21. Pacana J, Kozik B, Budzik G. Strength analysis gears in dual path gearining by means of FEM. Diagnostyka. 2015; 16 (1): 41-46.

22. Fudali P, Pacana J. Application development for analysis of bevel gears engagement using FEM. Diagnostyka. 2015; 16 (3): 47-51.

23. Marciniec A, Sobolewski B. Modeling and simulation of bevel gearboxes in CAD environment. Diagnostyka. 2015; 16 (3): 69-72.

24. Bjionowski B. A practical approach for modelling a bevel gear. Geartechnology. 2015; March/April: 6875.

25. Sokolov V, Krol O, Stepanova O. Choice of correcting link for electrohydraulic servo drive of technological equipment. In: Ivanov V. et al. (eds) Advances in Design, Simulation and Manufacturing II. DSMIE 2019, LNME, Springer, Cham 2020; 4: 702 710. https://doi.org/10.1007/978-3-030-22365-6_70

26. Sokolov V, Krol O, Stepanova O. Nonlinear simulation of electrohydraulic technological equipment. J. Physics: Conf. Series. VSPID20182019; 1278: 012003. https://doi.org/10.1088/1742-6596/1278/1/012003

27. Ivanov V, Dehtiarov I, Pavlenko I, Liaposhchenko O, Zaloga V. Parametric optimization of fixtures for multiaxis machining of parts. In: Hamrol A., Kujawińska A., Barraza M. (eds) Advances in Manufacturing II. MANUFACTURING 2019. Lecture 
Notes in Mechanical Engineering. Springer, Cham 2019; 2: 335-347. https://doi.org/10.1007/978-3-030$\underline{18789-7 \quad 28}$

28. Kotliar A, Gasanov M, Basova Y, Panamariova O, Gubskyi S. Ensuring the reliability and performance criterias of crankshafts. Diagnostyka. 2019; 20(1): 2332. https://doi.org/10.29354/diag/99605

29. Krol O, Sokolov V. 3D modelling of angular spindle's head for machining centre. J. Phys.: Conf. Ser. VSPID-2018 2019; 1278: 012002. https://doi.org/10.1088/1742-6596/1278/1/012002

30. Krol O, Sokolov V. Modeling Carrier System Dynamics for Metal-Cutting Machines. International Russian Automation Conference (RusAutoCon) 2018, IEEE, Sochi 2018; 1-5. https://doi.org/10.1109/RUSAUTOCON.2018.8501799

31. Zamriy AA. Practical training course CAD/CAE APM WinMachine. Teaching aid. Moscow: APM Publishing house, 2007. Russian.

32. Kondrashova SG, Khamidulina DA, Lashkov VA. Engineering design of mechanisms using the APM WinMachine system. Bulletin of Kazan Technological University 2011; 19: 193-198. Russian.

33. Shelofast VV, Chugunova TB. Fundamentals of machine design. Examples of problem-solving. Moscow: APM Publishing house, 2004. Russian.

34. Worm gears, cylindrical. Modules and worm diameter factors. GOST 19672-74. Moscow: Publishing Standards, 1979. Russian.
35. Transmission worm cylindrical gearboxes of generalpurpose. Strength and seizing calculations. Moscow: NIIMash Publishing, 1982. Russian.

Received 2020-08-05

Accepted 2020-11-02

Available online 2021-01-04

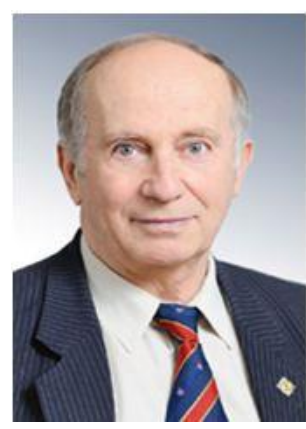

Oleg KROL (ORCID 00000003-0193-2750), PhD, Professor of the Machinery engineering and applied mechanics department of the Volodymyr Dahl East Ukrainian National University, Severodonetsk, Ukraine.

Main directions of scientific research: 3D- and parametrical modelling, machine tool design, CAD/CAM/CAE system, optimization in mechanical engineering, mechanical transmission reliability

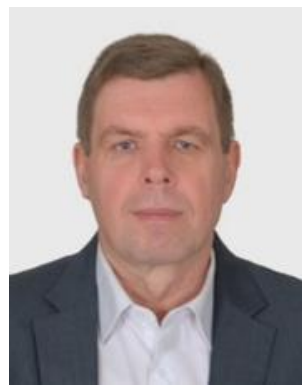

Volodymyr SOKOLOV (ORCID 0000-0003-04591824), Doctor of Sciences, Head of the Machinery engineering and applied mechanics department of the Volodymyr Dahl East Ukrainian National University, Severodonetsk, Ukraine.

Main directions of scientific research: automatic drives of technological equipment, dynamics and regulation of technological systems. 